\section{Saúde mental no Programa Saúde da Família: caminhos e impasses de uma trajetória necessária}

\author{
Mental health and the Family Health Program: \\ pathways and obstacles in a necessary approach
}

\author{
${ }^{1}$ Faculdade de Enfermagem, \\ Universidade Federal de \\ Mato Grosso, Cuiabá, Brasil. \\ 2 Secretaria Municipal de \\ Saúde de Cuiabá, Cuiabá, \\ Brasil. \\ ${ }^{3}$ Secretaria Estadual de \\ Saúde de Mato Grosso, \\ Cuiabá, Brasil. \\ Correspondência \\ R. Lucchese \\ Faculdade de Enfermagem, \\ Universidade Federal de \\ Mato Grosso. \\ Av. Margon 150, Catalão, GO \\ 75711-020, Brasil. \\ roselmalucchese@hotmail.com
}

\begin{abstract}
The focus of this study is mental health care in the Brazilian Family Health Program (FHP), with the complexity of such care as the main premise. The objectives were to analyze the actual conditions of mental health care in FHP services in Cuiabá, Mato Grosso State, describing the dynamics of such care and identifying situations and instruments used by different health professionals in dealing with problems of mental distress in the community. By means of a descriptive exploratory methodology, the discourses of eight health teams were studied, using content analysis. The study concluded that the demand for care for individuals with mental distress was not recorded on the patient charts, nor was it part of a proposal for individual or family interventions; some measures were taken according to a lay concept of "mental illness" and treatment, while referral to the specialized mental health care network was frequently used, despite its precariousness, thus reflecting the need for continuing training in mental health.
\end{abstract}

Mental Health; Family Health Program; Health Personnel
Roselma Lucchese 1

Alice Guimarães Bottaro de Oliveira 1

Marta Ester Conciani 2,3

Samira Reschetti Marcon 1

\section{Introdução}

Nos últimos vinte anos a área da saúde mental, no contexto nacional, vem se conduzindo em um processo complexo de auto-afirmação por um saber/fazer que supere o modelo biomédico, medicalizante e hospitalocêntrico; busca sustentar-se sobre dispositivos de atenção comunitária, territoriais, focalizados na pessoa em sofrimento psíquico e sua família, por meio de uma praxis transformadora e em constante construção. Em construção por estarmos diante do novo e desconhecido modo de fazer saúde mental na perspectiva psicossocial, remetendo-nos à necessidade de constituir um saber/fazer não reproduzido, que atenda demandas não declaradas anteriormente, pois a praxis fundamentada no modelo biomédico e a lógica de ser dos hospitais psiquiátricos era e é de domínio dos profissionais que atuavam na psiquiatria; vigiar, excluir, isolar e ofertar medicamentos são saberes que atendem ao tratamento da doença mental. Já atender o sujeito em sofrimento psíquico e sua família nas dimensões sociais, de inclusão, reabilitação psicossocial, inserção comunitária e na produção social de vida, integrando trabalho, lazer, cultura, educação e saúde não são ações naturalmente prescritas nos compêndios e manuais de saúde mental e psiquiatria.

Muitos domínios científicos e tecnológicos inovadores, que atendem as questões psicossociais estão sendo efetivados e ou descobertos 
no dia-a-dia dos serviços que superaram a reprodução do fazer e "arriscaram" transformar as relações internas de gestão e trabalho. Assim, concretizam atividades pioneiras de substituição à hospitalização do usuário ${ }^{1}$. Os serviços referidos são, em sua maioria, os Centros de Atenção Psicossocial (CAPS), equipamentos do nível especializado de atendimento aos portadores de transtorno mental. Mas, sabemos que apenas a estruturação de CAPS para atender a saúde mental na perspectiva psicossocial não basta, é necessário que os diversos níveis de atenção à saúde formem uma rede precisa, que responda as demandas da saúde mental em co-responsabilidade com a comunidade. Assim, o nível primário de atenção se apresenta como um "espaço" privilegiado para que esse envolvimento ocorra, pois a Organização Mundial da Saúde (OMS) ao recomendar ações definidoras do modelo de atenção em saúde mental, ressaltou a importância da atenção primária para garantir o tratamento na comunidade 2 .

No país, a estratégia do Sistema Único de Saúde (SUS) para efetivar suas diretrizes e assegurar à população brasileira o acesso a cuidados primários e à melhoria de sua qualidade de vida é o Programa Saúde da Família (PSF). Acreditamos que articulações entre PSF e atenção à saúde mental na lógica da Reforma Psiquiátrica podem ocorrer, uma vez que ambos têm princípios e diretrizes que se convergem: a busca em romper com o modelo médico hegemônico, o desafio de tomar a família em sua dimensão sócio-cultural como objeto de atenção, de planejar e executar ações num determinado território, promover cidadania/participação comunitária, e constituir novas tecnologias para melhoria da qualidade de vida das pessoas.

Mas, as aproximações destes modelos situam-se mais nas convergências "do modo que deveria ser" de cada um. Observa-se um relativo desconhecimento da realidade sobre as necessidades de saúde mental na atenção primária em todo o Brasil, pois apesar da marcante presença das demandas de saúde mental nas áreas de abrangência dos PSF, as equipes, freqüentemente, expressam dificuldades de identificação e acompanhamento das pessoas com transtorno mental nas comunidades. Associado a isso, observa-se que os indicadores disponíveis nos sistemas de informação municipal, regional e nacional dão conta somente de informações sobre internações em hospitais psiquiátricos ou de internações por transtorno mental em hospitais gerais e de atendimento em CAPS 3.

Atender saúde mental no nível primário é um processo complexo, há operação de uma "complexidade invertida", ao tomarmos o pressuposto tradicional de que temos no SUS uma hierarquização, e que a cada um dos níveis de atenção à saúde (primário, secundário, terciário) corresponde um nível de complexidade (do menor para o maior), temos que o cuidado hospitalar é mais complexo 4 . Entretanto, a complexidade observada aí é somente aquela relacionada ao consumo de "tecnologias duras" 5 , ou àquelas tecnologias materiais relacionadas à indústria farmacêutica e de equipamentos médicos. No campo da atenção psiquiátrica, observamos que os procedimentos realizados nos hospitais psiquiátricos são "procedimentos simples e que tendem à simplificação" 4 (p. 108), pois a própria vida do paciente nesses locais vai se conduzindo, quanto maior for o período de internação, numa lógica de perda da complexidade e padronização simplificada típica da institucionalização: horário de acordar, de banho, de alimentação; local único de circulação, até mesmo o lazer é padronizado em locais e acontecimentos repetitivos. De certo modo, o mundo é posto dentro da instituição, pois há um controle total dos espaços-tempos nos hospitais psiquiátricos 4,6 .

De modo muito diverso, ao abordarmos a atenção à saúde mental no nível primário, assumimos o desafio de trabalhar com as pessoas em sofrimento mental no seu mundo real e esse cuidado é “complexo, porque [está situado] no atravessamento do território geográfico com o território existencial [e, assim,] somos obrigados a fabricar mundos" 4 (p. 109) ou, a habitar mundos criados por pessoas que vivenciam experiências diferentes, como por exemplo, o mundo de quem usa drogas ou de quem apresenta um delírio numa determinada comunidade.

Admitindo essa complexidade, sabemos que as iniciativas de ações de cuidado em saúde mental no PSF podem, em algumas situações, ser reduzidas à medicalização de condições de sofrimento ou ainda, de entendermos a realidade por meio das intenções expressadas constituindo um discurso idealizado. Assim, buscamos um investimento teórico-prático no trabalho/cuidado em saúde mental comunitário e, assumindo a necessidade de uma constante verificação da realidade, recorremos a esta pesquisa, que teve como objeto o modo concreto de organização tecnológica do trabalho em saúde nas unidades de PSF da região norte do $\mathrm{Mu}$ nicípio de Cuiabá, Mato Grosso, Brasil, intencionado a evidenciar a sua configuração local, reconhecer os possíveis avanços assistenciais e potenciais acumulados, bem como as práticas cotidianas de trabalho das equipes de saúde da família na atenção à saúde mental, haja vista o seu histórico distanciamento, pois a assistência às pessoas com sofrimento psíquico e familia- 
res sempre foi segregada e dispensada nos hospitais psiquiátricos, distantes das cidades e da rede geral de serviços de saúde.

\section{Objetivos}

Identificar as condições concretas da assistência à saúde mental realizada nas equipes de saúde da família; descrever a dinâmica assistencial da equipe de saúde da família nas situações de sofrimento mental; analisar as práticas de saúde dos trabalhadores de saúde das equipes de saúde da família na abordagem aos portadores de transtornos mentais.

\section{Metodologia}

Esta foi uma pesquisa exploratória descritiva desenvolvida na região norte do Município de Cuiabá, onde há concentração de maior número de equipes de saúde da família, com 16 equipes, porém foram escolhidas aquelas com tempo mínimo de dois anos de funcionamento na época da coleta dos dados, totalizando oito delas. Julgamos este o tempo necessário para efetiva implantação das ações, uma vez que o objeto de análise foi a organização das práticas de saúde das equipes.

No ano de 2004 foi realizada uma capacitação para $100 \%$ das equipes de saúde da família dessa região, com o objetivo de capacitar os trabalhadores de saúde para atender pessoas portadoras de transtorno mental incorporando a atenção psicossocial na atenção à saúde da família, reconhecendo a equipe de saúde da família como serviço integrante da rede de atenção psicossocial. As equipes pesquisadas participaram desse processo de capacitação em saúde mental.

O projeto desta pesquisa foi aprovado pelo Comitê de Ética em Pesquisa do Hospital Universitário Júlio Müller (HUJM - 176/CEPHUJM/2004) conforme a Resolução $n^{o}$. 196/96 do Conselho Nacional de Saúde. O trabalho de campo foi formalizado com solicitação à Secretaria Municipal de Saúde (SMS).

As técnicas de coleta de dados foram a observação participante e entrevista semi-estruturada, a partir das seguintes questões norteadoras: "Existem pessoas portadoras de transtorno mental na área de abrangência dessa unidade de saúde da família?"; "Atende pessoas portadoras de transtorno mental no trabalho realizado na unidade de saúde da família?" (se a resposta for afirmativa); "Fale sobre esses atendimentos". As entrevistas foram gravadas e transcritas na íntegra.
Foram entrevistados 63 trabalhadores, sendo 13 profissionais de nível superior das unidades de saúde da família, codificados em PNS, entre eles 7 enfermeiros e 6 médicos; 12 profissionais de nível médio, PNM (técnicos e auxiliares de enfermagem) e 38 agentes comunitárias de saúde, ACS. As entrevistas foram realizadas após o consentimento prévio dos participantes.

Os discursos dos sujeitos passaram pela análise de conteúdo, técnica categorial temática originando os temas e subtemas: “...tema é uma unidade de significação que se liberta naturalmente de um texto analisado segundo certos critérios relativos à teoria que serve de guia à leitura" 7 (p. 105).

A discussão dos temas que emergiram fundamentou-se no referencial teórico-metodológico da dialética marxista. Consideramos que o trabalho foi a categoria analítica que nos deu a baliza necessária ao conhecimento da organização tecnológica da assistência em unidades de saúde da família diante da atenção à saúde mental. Compreendendo o trabalho na perspectiva da historicidade articulada ao modo de produção ${ }^{8}$, esta categoria foi central para a análise estrutural do modo de conformação das práticas de saúde, considerando sua potencialidade explicativa interna.

\section{Resultados e discussão}

Buscamos identificar as práticas de atenção à saúde mental no cotidiano das equipes de saúde da família, a partir da identificação dos elementos básicos deste processo: o próprio trabalho realizado, ou a atividade orientada a um fim, o objeto de trabalho e os instrumentos ou meios de trabalho. Esses três elementos conformam processos, em um continuum interdependente 8 .

O trabalho humano pressupõe uma intencionalidade. Para que algo se constitua como objeto de trabalho, há necessidade de que haja, a partir dele, a construção abstrata, "pensada", de um resultado ou de um objetivo que se quer atingir. Para que esse objetivo ou resultado seja alcançado, faz-se necessário utilizar instrumentos ou meios de trabalho que também são criados ou utilizados mediante a intencionalidade do processo. A mediação entre o trabalhador e o objeto de trabalho se dá pelos meios ou instrumentos de trabalho. Num sentido estrito, os meios de trabalho constituem-se pelas ferramentas que o homem constrói e utiliza; em sentido amplo, os meios de trabalho são todas as condições objetivas existentes para que o processo de trabalho se realize 8 . 
Nas práticas de saúde o ser humano realiza uma atividade de transformação do objeto de intervenção, utilizando meios de trabalho, pretendida desde o princípio. Desse modo, as informações sobre esses elementos do fazer que integram um continuum micro e macro social, nos relatos dos entrevistados, conformaram os temas e sub-temas a seguir.

Tema 1: (des)caminhos no atendimento a pessoa em sofrimento psíquico

Houve um reconhecimento da demanda da atenção em saúde mental nas equipes de saúde da família por parte de todos os sujeitos da pesquisa.

PNS: “Tem, vários. Várias pessoas com doença mental".

PNS: "Temos pessoas... sim. Realmente da área temos várias pessoas com transtorno mental”.

Ao reconhecerem a demanda revelaram, discursivamente, a sua produção social, depreendendo os seguintes subtemas.

\section{- Subtema 1.1: atendendo da forma como é possível}

Atender a pessoa em sofrimento psíquico dispensa tempo e paciência do trabalhador de saúde.

PNM: “A única coisa que a gente pode fazer é orientar que tem que ter paciência, cuidado com eles".

Além da exigência de envolvimento do trabalhador, revelaram que sua produção na área da saúde mental não é sistemática e tampouco planejada, tudo é feito informalmente no ato do contato com a pessoa em sofrimento psíquico, conforme ela se apresenta no serviço. Não há planejamento para a identificação e descrição dessa demanda, de organização do trabalho para o atendimento em grupos ou desenvolvimento de estratégias de atenção ao usuário.

PNS: "Só tem quando ele vem na unidade, a gente não vai, não faz aquele trabalho como a gente faz, tipo hipertensão...”.

PNS: "Grupos tem, agora o único que não tem é o da saúde mental".

PNS: "Quando procuram, individualmente a gente orienta...”.

Observa-se um fazer que não se enquadra como prescritivo nem criativo, tem características de improvisação. São ações que não se norteiam na competência profissional burocrática, pois não se revestem de uma concepção de funções, rotinas, normas estabelecidas em um determinado serviço, como um modelo herdado do Taylorismo e Fordismo, no qual o sujeito é um operador com competência limitada a saber executar operações prescritas 9 .
Por outro lado, são fazeres que também não são gerenciados por uma competência na perspectiva da economia do saber. Nesta, o sujeito é considerado um ator, aquele que vai além do prescrito; o profissional sabe agir, tem iniciativa, tem a capacidade de desencadear e conjugar recursos (saber, saber/fazer, outros) e ações, portanto, não haveria uma única maneira de fazer, em um universo de condutas 9 . O gerenciamento caracteriza-se pela condução, proporcionando a emergência da competência no contexto profissional, portanto, não é esta produção social que foi evidenciada nos discursos dos sujeitos.

Consideramos que o saber prescritivo das competências profissionais burocráticas não poderia responder às demandas do cuidado complexo requerido pela atenção à saúde mental no nível primário e, a conjugação de recursos necessária para a lida com o sofrimento mental nas comunidades não foi desenvolvida na formação profissional dos sujeitos, pois não é regularmente encontrada na formação de médicos e enfermeiros, nem está posta como rotina em uma trajetória histórica de segregação dos portadores de sofrimento psíquico nos hospitais psiquiátricos. Assim, os dados apontam uma demanda que já "saiu do lugar", pois não está mais internada nos hospitais psiquiátricos, mas, visível para as equipes de saúde da família, entretanto, não é objeto dessa prática de saúde, no sentido de não merecer, por parte dessas equipes, um planejamento de cuidado, que expressaria uma intencionalidade da atenção.

Dessa forma, as necessidades de saúde mental já são visíveis para as equipes de saúde da família, mas ainda não se incorporam como objetos de suas práticas de saúde, a não ser em situações pontuais quando se observam ações relacionadas à medicação, como o fazer mais valorizado na restrita atenção à pessoa em sofrimento psíquico.

PNS: "O atendimento na área de saúde mental feito na unidade acaba se restringindo à medicalização...".

As dificuldades apresentadas pelas equipes de saúde da família na abordagem das situações complexas demandadas pelas pessoas e famílias portadoras de transtorno mental encontram, muitas vezes, o recurso da medicalização como única possibilidade. Há necessidade de que, nas equipes de saúde da família, não sejam priorizados os recursos tradicionais de tratamento da psiquiatria, como consulta especializada psiquiátrica ou psicológica e medicação, para que possamos reconhecer que a pessoa é "primeiro um cidadão e depois um quadro psicopatológico" 10 (p. 19). 
Diante das dificuldades para a abordagem do sofrimento mental minimamente embasada em referenciais teórico-técnico-assistenciais, muitas ações presenciadas são fundadas em concepções místicas ou leigas, estereotipadas sobre o portador de transtorno mental, mobilizando nos profissionais mais um fazer empírico do que clínico-assistencial.

ACS: "é obrigado a cuidar... é... eu morro é de medo...”.

ACS: “... uma paciente que andava pelada, fazia cada coisa... meu Deus! Eu tinha até medo...”.

Observamos nos discursos dos ACS uma maior freqüência de expressões relacionadas ao medo e dificuldades de interação com pessoas em sofrimento mental. Nas equipes de saúde da família, o ACS é quem convive na comunidade e, obrigatoriamente, se depara com as pessoas que são, simultaneamente, seus vizinhos e objetos de seu acompanhamento. Pela precariedade ou ausência de informação, muitas vezes há uma dificuldade no reconhecimento e discernimento de situações que envolvem alterações de comportamento, como sofrimento mental.

Entretanto, essa dificuldade não necessita ser permanente ou imóvel. Algumas experiências de trabalho de saúde mental na equipe de saúde da família apontam que o envolvimento dos ACS no processo sistemático de acompanhamento dos casos repercute em ações diretas e indiretas de educação em saúde de grande alcance e complexidade no sentido de construção do modelo de atenção psicossocial 10,11. Ao serem desenvolvidas ações de cuidado de saúde mental no PSF desenvolvem-se, portanto, além dessas ações de cuidado direto e inclusão social de pessoas em sofrimento psíquico, competências para a abordagem de situações complexas. Compreendemos que esse deve ser o enfoque das capacitações em saúde mental para o PSF.

\section{- Subtema 1.2: atenção negada}

A atenção negada emergiu das unidades de significados que revelaram o quanto a pessoa em sofrimento psíquico tem dificultado o acesso à assistência que atenda suas necessidades, das mais simples às mais complexas.

PNS: “... porém estes dados [de necessidades de saúde mental] não são registrados no prontuário, por não achar conveniente".

PNM: “... nós não temos como estar acompanhando direitinho, acompanhando esses pacientes, precisam mesmo é da família pra ajudar".

PNM: “Nós não tratamos essas pessoas...”.

Os trabalhadores das equipes de saúde da família discursaram sobre uma clientela que não tem registro, não é sequer identificada na unidade de saúde da família, o que talvez seja um comportamento reprodutor da fragilidade do sistema de informação (Sistema de Informação sobre Atenção Básica - SIAB), o qual não dá visibilidade para os portadores de transtorno mental, interferindo drasticamente nas ações programáticas para atenção básica a esta população, bem como no comportamento do sistema de saúde que negligencia ao não ter dados para programar, planejar ações de saúde mental na atenção primária.

A histórica segregação dos portadores de sofrimento mental nos hospitais psiquiátricos possibilita essa cultura na qual a equipe de saúde da família se responsabiliza pelos atendimentos à saúde da população, "exceto" a saúde mental. Essa expressão cultural que concebe o cuidado na atenção primária revela uma dicotomia mental-físico já amplamente superada na discussão teórica da integralidade da assistência à saúde, mas ainda muito distante da realidade das equipes de saúde da família.

Assim, todo este cenário negligenciador contribui para uma realidade de "não ser assistido", ficando a pessoa em sofrimento psíquico e sua família à mercê da própria sorte e invisíveis para o sistema de atenção à saúde.

ACS: “... essas três pessoas que eu citei aí pra você, elas não tratam em lugar nenhum!”.

PNM: “... na USF [unidade de saúde da família] vem pouco cliente com problema mental, a gente quase não tem contato...".

No cotidiano do trabalho e durante o processo de capacitação, alguns trabalhadores expressaram de modo livre a idéia de que assumir o cuidado para com as pessoas em sofrimento mental no nível primário da atenção é um acréscimo às suas já grandes responsabilidades profissionais e, conseqüentemente, investem em não desenvolver nenhuma ação nesse sentido. Nas entrevistas, este "problema a mais" foi traduzido como uma ausência de competência para lidar com a situação que é complexa devido à insuficiência da formação, ou pela não estruturação de uma equipe especializada. Essa questão foi sempre focada na necessidade do tratamento especializado/medicalização.

PNS: "Elas [ACS] não têm uma postura ética adequada que teria que se ter, então dá muito problema [pra atender o doente mental]”.

PNM: “... que tinha que ter um psicólogo pra estar orientando... tinha que ter um profissional aqui... De apoio, né, pra não chegar a ter um transtorno mental...".

PNM: "A maioria deles não fazem um tratamento... porque a médica daqui não é psiquiatra". 
Pensar no processo de reorientação do modelo assistencial em saúde mental, incluindo a atenção primária é também considerar a questão da formação de trabalhadores, conforme destacado na III Conferência Nacional de Saúde Mental 12, a necessidade de investir na gestão de pessoas para a construção do novo modelo assistencial, nas dimensões de potencialidades das pessoas, inserção nas políticas e projetos públicos. Todo este processo envolve tanto a análise da situação atual de inserção dos trabalhadores no SUS, fortemente marcada pela precarização, como a compreensão dos problemas atuais e a elaboração de respostas 12 .

\section{- Subtema 1.3: atendendo as demandas físicas (no modelo biomédico)}

Compreendemos que o modo de produção configura-se como um conceito abstrato formal e como modelo teórico de aproximação da realidade, então, por intermédio desta pesquisa, podemos inferir que o modelo teórico que rege a prática de vários profissionais das equipes de saúde da família é o modelo biomédico.

PNS: "Você tem que ficar preocupada com outras patologias, com outras doenças".

PNS: "Elas procuram a unidade somente para o atendimento em clínica médica elou ginecologia, aí o profissional pergunta da medicação psiquiátrica e o estado do usuário".

O modelo de atenção que mais instrumentaliza o trabalhador de saúde, e chamamos a atenção para as falas acima de profissionais de nível superior, foi o biomédico, na dimensão de cuidar do físico, de incluir sistematicamente o atendimento da pessoa em sofrimento psíquico apenas nas questões orgânicas, somente assim este sujeito torna-se visível. Por outro lado, mostraram a "padronização" das ações a partir dos programas do Ministério da Saúde.

PNS: "Não especificamente o atendimento à saúde mental, às vezes eles voltam com outros problemas, e aí o atendimento é feito aqui".

O paradigma biomédico é a opção privilegiada por parte dos profissionais da área da saúde, e este comportamento está intimamente relacionado à formação acadêmica e profissional, em razão da primazia de crer em uma explicação lógica à doença e à cura. Esta situação cria um verdadeiro descompasso entre os paradigmas biomédico e psicossocial, tanto no âmbito da prática clínica como na prestação de cuidados ao doente mental. O padrão biomédico não abrange a problemática da saúde mental em sua totalidade 13 .

PNM: "Vem, vem pra pedir receita azul às vezes, ou vem pra pedir, pra pegar remédio...”.
- Subtema 1.4: rompendo paradigmas, transformando a prática

A presente pesquisa também nos permitiu observar um fenômeno diferenciador no modo de ver e discursar sobre a atenção à saúde mental, traduzido em um passo bastante tímido, porém, relevante para a transformação da prática e rompimento com o poder hegemônico do modelo biomédico. Revelaram uma disposição para responsabilizar-se perante a prevenção, o acompanhamento e tratamento da pessoa em sofrimento psíquico.

PNS: "Pra prevenção de até algum surto. Porque a gente pode prevenir, né?! E às vezes não acontece".

PNS: "Porque a gente consegue vê o doente como um todo, aborda toda a família e vê de forma holística, então é mais eficiente o trabalho na recuperação e manutenção da saúde... Eles acham que só o especialista que sabe".

A responsabilização e a produção de vínculo terapêutico são objetos provedores de reforma e ampliação da clínica e das práticas de atenção integral à saúde, e dependem fundamentalmente da constituição de novos padrões de relacionamento entre os profissionais de saúde e os usuários dos serviços 14. Convém lembrar que as mudanças de padrões de relacionamento têm determinantes que vão além da simples vontade e disponibilidade do trabalhador em transformar seu fazer, são influenciados, também, pelos estilos de gestão e da estrutura de poder existente nas instituições. Por exemplo, o descompromisso e falta de interesse de participação na maioria dos trabalhadores podem ser gerados no interior do serviço de saúde onde as decisões são tomadas por um pequeno grupo que centraliza o poder, que por sua vez é organizado com base no poder das corporações profissionais 14 .

A descoberta de alguns profissionais é de que algumas práticas são possíveis, e assim, seguem construindo um fazer diferenciado, como a relevância da família.

PNM: "Então eu acho que... começar pela família, trabalhar com a família também”.

Ou com atitudes que, a princípio, parecem simples, mas requerem o desenvolvimento de competências essenciais, que mobilizam recursos dos profissionais em diversas áreas do saber, como o saber agir e reagir com pertinência ${ }^{1}$, no qual requer:

Saber posicionar-se:

PNM: "Ela era depressiva, teve uma perda do marido e eu ajudei ela muito, às vezes nem sabia, comecei a ajudar ela sem saber o problema. Ai fui entrando na situação". 
Saber agir diante da pessoa que tem dificuldade para ser ouvida, de se relacionar com o outro e estabelecer uma ação:

PNM: "E ai você começa a observar ela mais, conversar mais, ver o porquê disso... você tem que observar!".

PNM: "E o transtorno mental cada paciente que chega, cada caso é um caso, ai você tem que olhar, observar e tentar se aproximar da pessoa".

Saber atender integralmente o paciente:

PNM: "Chamei ela ali na sala da enfermeira, sentei ela e comecei a conversar. Expliquei para ela que a pressão dela tava bem, por que verificar tanto a pressão?... Começou a chorar... ia se matar...".

Emergiram das falas, essencialmente dos ACS, outra formas de superação da prática medicalizante, com a aproximação, a visibilidades da singularidade do processo saúde doença, na disponibilidade de ajudar.

ACS: “... Tem um sintoma diferente do outro. Nenhum é igual. Assim como todos nós... a gente tem as nossas diferenças. A gente tem que trabalhar com diferenças".

ACS: "A gente tem que compreender eles. Procurar ouvir e não só ficar falando... tá junto”.

ACS: “... Eu chego na casa dela, começo a conversar com ela, assunto que não tem nada a ver, às vezes até sobre o quintal, da casa dela, algum assunto, de repente ela tá sorrindo e passa aquela agressividade".

São com estas atitudes que os ACS conquistam a confiança na relação da pessoa em sofrimento psíquico e sua família, e promovem elos entre família e equipe de saúde da família.

ACS: “... Sem nós lá na frente muito fica a desejar, porque até durante visitas com médico e enfermeiro é pra gente que eles direcionam a palavra".

Na prática da relação com a pessoa em sofrimento psíquico, aprenderam que os recursos a serem instrumentalizados são muito mais do âmbito pessoal, das relações - "tecnologias leves" 5, do que nas tecnologias materiais, equipamentos. Estes recursos que tiveram um caráter formativo, passível de ser investido como uma tecnologia, que é apreendida e desenvolvida no aprimoramento contínuo, na compreensão de si mesmo e de suas próprias relações, no cotidiano da vida pessoal e profissional. "O profissionalismo é um produto da história do profissional e de seu percurso biográfico, quer trate-se de sua vida pessoal, social ou profissional. Esta é uma das importantes fontes da confiança que lhe é concedida. O cliente do profissional se fia mais na sua experiência do que em seus diplomas" 9 (p. 77).
Tema 2: a (des)articulação das relações da atenção em saúde mental na equipe de saúde da família com a rede de atenção à saúde de Cuiabá

Na cidade de Cuiabá a atenção à saúde mental, historicamente foi atendida pelo hospital psiquiátrico, que ocupa um espaço social relevante para a população regional. Esta situação, aparentemente tornou-se uma condição cômoda para gestores e trabalhadores da saúde, visto que a responsabilidade pelo doente mental ficou a cabo deste hospital, contudo, é comum ouvirmos de alguns profissionais e da população que é este hospital o local que acaba sempre cuidando das crises/surtos do portador de transtorno mental. Além do hospital, existem dois CAPS para transtorno mental severo - I e II, um CAPS infantil e um CAPSad (para usuários de substâncias psicoativas) e residências terapêuticas que ainda têm o hospital como serviço centralizador das ações de saúde mental o hospital. Quanto às equipes de saúde da família, nos parecem permanecer à margem desta rede, neste contexto sua relação, muitas vezes, resumiu-se ao encaminhamento ao serviço de referência em saúde mental, não em uma lógica porta de entrada como referência e contra-referência, mas em um contexto do "não saber o que fazer" e nem "o que foi feito". Vejamos o subtema a seguir.

\section{- Subtema 2.1: "encaminhoterapia" - empurrando a "batata quente"}

Este subtema emergiu, na sua maioria, das falas dos PNS e de PNM que ao descreverem a forma de atendimento das pessoas com problemas mentais revelaram que a prática mais comum é o encaminhamento, isto é, estar diante do doente é estar tão "desinstrumentalizado" para o fazer que a única alternativa é encaminhar para um serviço especializado.

PNM: “... que esses problemas, assim, não são resolvidos na unidade, são encaminhados!”.

PNM: "Encaminha pro Adauto Botelho, aí o Adauto Botelho faz os primeiros cuidados, primeiros atendimentos, de lá ele manda pro CAPS. Essas foram as informações".

Os trabalhadores das equipes de saúde da família acabam encaminhando na condição de "enviar" o sujeito que lhe apareceu à frente em surto, para o local reconhecido socialmente como capaz de lidar com esta situação, "o hospital psiquiátrico", e de lá eles "receberam informações" de que ele seria "novamente" enviado a um CAPS. Os trabalhadores da equipes de saúde da família reproduzem a cultura manicomial, em que o hospital é quem organiza a rede de atenção 
à saúde mental, é notório que ele recebe a pessoa em condição aguda, aliviando momentaneamente a comunidade, família, mas não oferece um cuidado de qualidade 11 .

Observa-se que a porta de entrada na rede de atenção à saúde mental se deu pela atenção primária, porém há neste acontecimento fenômenos preocupantes: primeiro o questionamento da capacidade resolutiva da equipe de saúde da família, visto que ela no SUS representa uma possibilidade para a inversão do modelo centrado na doença, e que teria seu poder resolutivo fundamentado na capacidade de descartar parcialmente os encaminhamentos para os níveis mais complexos de atenção e reduzir a excessiva "medicalização" das ações de saúde 15.

Segundo revelou a fragilidade dos dispositivos extra-hospitalares de atenção à saúde mental, na lógica da atenção psicossocial o CAPS deveria ser o regulador da porta de entrada na rede de atenção à saúde mental 16, aqui se tornou invisível nesta relação. A modalidade de CAPS I e II, como no caso estudado, por prestar atenção diurna e funcionar com equipe reduzida, limita o atendimento a horários específicos e em quantidade reduzida, justificando sua pouca condição em ser substitutivo a hospitalização psiquiátrica na rede de atenção à saúde mental, prevalecendo o status do hospital como a possibilidade de atendimento da crise 11, mesmo sabendo previamente da baixa resolubilidade deste atendimento.

PNS: “... era um rapaz da área da Carla ou da Camila [nomes fictícios de ACS]... ele veio e pediu [um encaminhamento para o CAPS], não sei se já conseguiu... Lá até que é bom, o duro é conseguir, né".

PNS: "Encaminhamento pacientes mais graves, para o psiquiatra... Só que eu não tenho contra-referência".

A responsabilização e vínculo, recursos terapêuticos indispensáveis para a consecução dos objetivos tanto do PSF quanto da atenção psicossocial são $3,4,10$, nas situações estudas, rarefeitas ou ausentes. Descreveram relações fragmentadas, de intermináveis encaminhamentos, evidenciando uma desarticulação de ações, eu faço a minha parte "encaminho", para o outro fazer a parte "dele", que também não sei qual "foi”.

Vale destacar que este processo de "encaminhoterapia" nos remete ao questionamento da resolubilidade da ação, será, que as equipes dos outros níveis de atenção foram capacitadas e darão uma resposta efetiva para a situação encaminhada? Os serviços estão organizados e preparados para o "acolhimento" desta demanda? Diante da fragilidade da organização dos serviços o fluxo de atendimento à pessoa em sofrimento psíquico quase sempre termina no hospital psiquiátrico.
Num contexto de superação do modelo biomédico e da efetivação dos princípios do SUS, as equipes de saúde deveriam se constituir como equipes de referência ou equipes de referência territorial (num dado limite geográfico). Estas se organizam por meio da composição multiprofissional de caráter transdisciplinar, formadas segundo características e objetivos da própria unidade, e de acordo com a realidade local e disponibilidade de recursos. Cada equipe de referência assume a responsabilidade pela atenção integral do usuário, atento a todos os aspectos de sua saúde, elaborando e efetivando projetos terapêuticos e buscando outros recursos terapêuticos, quando necessário 14.

A meta por equipes multiprofissionais de caráter transdisciplinar está longe de ser alcançada, as equipes de saúde da família não dialogam com as equipes de referência especializada, não atendendo integralmente e transdisciplinarmente a atenção. Quando não se tem a equipe de referência com projetos terapêuticos constituídos com equipes de referência especializada, o usuário passa a ser de responsabilidade indefinida, isto é, de todos os profissionais/equipe e de nenhum, ao mesmo tempo, cada um se preocupa com a "sua" parte 14 .

\section{Considerações finais}

Consideramos que o avanço ou não no movimento de Reforma Psiquiátrica é resultado de um conjunto de ações de gestão, dos trabalhadores da saúde e da comunidade. Dentre elas focamos a necessidade de investimento permanente da gestão e dos trabalhadores diante das reais necessidades de saúde da comunidade.

O estudo revelou que a demanda de atendimento às pessoas com sofrimento mental era identificada e mencionada informalmente pela equipe, não era registrada nos prontuários, nem integrava o projeto de intervenção/cuidado individual ou familiar. Das equipes de saúde da família estudadas, apenas os profissionais de uma equipe relataram realizar sistematicamente a identificação e acompanhamento medicamentoso de pessoas com transtorno mental e família. Observamos que algumas ações eram realizadas por alguns profissionais no sentido de acolher e intervir, conduzidos por uma concepção leiga de "doença mental" e tratamento.

Também nos indicou alguns entraves para a efetivação da atenção psicossocial, sobretudo a prevalência da lógica "manicomial" e "medicalizante” na condução da dinâmica da rede local de atenção à saúde mental. O hospital psiquiátrico permanecia como o centro do atendimento 
da pessoa em crise, tomando para si a figura de regulador da rede de saúde. O dispositivo CAPS permaneceu em um local intocável, e desarticulado do restante da rede de atenção à saúde mental.

Neste contexto a equipe de saúde da família permanecia à margem de toda a rede, não soube como lidar com o sujeito que sofre mentalmente em sua base territorial, e quando se via diante da crise recorria ao hospital, vista a dificuldade de acesso ou a ausência de referência contra-referência com os CAPS locais.

Uma possibilidade de superar a desarticulação da rede de atenção à saúde mental, e reduzir a distância histórica da inexistência da atenção primária na área, seria a constituição do que já está prescrito pelo Ministério da Saúde 12,16: uma rede de saúde mental extra-hospitalar forte, consistente, co-responsável na construção de ações de saúde em conjunto; um trabalho encravado na comunidade com a finalidade de promover a mudança da concepção de que "lugar de louco é no hospício"; ampliar o potencial das práticas acolhedoras "do momento da crise/surto" nos serviços extra-hospitalares; fazer valer a equipe matricial para a equipes de saúde da família (estreitar relação CAPS/ equipes de saúde da família), provendo-a de capacitações, apoio e supervisão; investimentos na formação dos trabalhadores da saúde tanto na acadêmica quanto na educação permanente.

Somos todos responsáveis diante das dificuldades relatadas nesta pesquisa, como já foi dito, estamos em construção de uma nova forma de pensar/saber e fazer saúde mental. Urge a necessidade de mudança de atitude dos trabalhadores e gestores em reconhecer e incorporar as manifestações de sofrimento psíquico como objetos de seu trabalho na atenção primária, além de romper com as barreiras da atenção formal e isolada da saúde, buscar parcerias intersetoriais e sociais.

\section{Resumo}

Esse estudo tem como objeto a atenção à saúde mental no Programa Saúde da Família (PSF) e como pressuposto a complexidade desse atendimento. Os objetivos foram analisar as condições concretas da assistência à saúde mental em unidades de PSF de Cuiabá, Mato Grosso, Brasil, descrevendo a dinâmica assistencial e identificando situações e instrumentos utilizados pelos diferentes trabalhadores para atender problemas de sofrimento mental na comunidade. Por meio de metodologia exploratório-descritiva, foram estudados os discursos de oito equipes com os recursos da análise de conteúdo. Concluiu-se que a demanda de atendimento às pessoas com sofrimento mental não era registrada nos prontuários nem integrava projeto de intervenção individual ou familiar; algumas ações eram realizadas numa concepção leiga de "doença mental" e tratamento, e o recurso do encaminhamento para a rede especializada era freqüentemente acionado, apesar da precariedade desta, refletindo a necessidade de continuidade no processo de capacitação em saúde mental.

Saúde Mental; Programa Saúde da Família; Pessoal de Saúde

\section{Colaboradores}

R. Lucchese participou da sistematização e análise dos dados e elaboração do artigo. A. G. B. Oliveira coordenou o projeto de pesquisa, participou da coleta de dados e elaboração do artigo. M. E. Conciani e S. R. Marcon contribuíram na coleta de dados da pesquisa e elaboração do artigo. 


\section{Referências}

1. Lucchese R. A enfermagem psiquiátrica e saúde mental: a necessária constituição de competências na formação e na prática do enfermeiro [Tese de Doutorado]. São Paulo: Escola de Enfermagem, Universidade de São Paulo; 2005.

2. Organização Mundial da Saúde/Organização PanAmericana da Saúde. Relatório sobre a saúde no mundo - saúde mental: nova concepção, nova esperança. Genebra: Organização Mundial da Saúde; 2001.

3. Oliveira AGB, Vieira MAMV, Andrade SMR. Saúde mental na saúde da família: subsídios para o trabalho assistencial. São Paulo: Editora Olho d'Água; 2006.

4. Lancetti A. Clínica peripatética. São Paulo: Editora Hucitec; 2006.

5. Malta DC, Merhy EE. A micropolítica do trabalho em saúde: revendo alguns conceitos. REME Rev Min Enferm 2003; 7:61-6.

6. Goffman E. Manicômios, prisões e conventos. São Paulo: Editora Perspectiva; 2003. (Coleção Debates).

7. Bardin L. Análise de conteúdo. Lisboa: Edições 70; 1977.

8. Mendes-Gonçalves RB. Tecnologia e organização social das práticas de saúde: características tecnológicas do processo de trabalho na rede estadual de centros de saúde de São Paulo. São Paulo: Editora Hucitec/Rio de Janeiro: ABRASCO; 1994.

9. Le Boterf G. Desenvolvendo a competência das profissionais. 3a Ed. Porto Alegre: Editora Artmed; 2003.
10. Lancetti A. Saúde mental nas entranhas da metrópole. In: Lancetti A, organizador. Saúde mental e saúde da família. São Paulo: Editora Hucitec; 2001. p. 11-52.

11. Oliveira AGB, Ataide IFC, Silva MA. A invisibilidade dos problemas de saúde mental na atenção primária: o trabalho da enfermeira construindo caminhos junto às equipes de saúde da família. Texto \& Contexto Enferm 2004; 13:618-24.

12. Conselho Nacional de Saúde, Secretaria de Assistência à Saúde, Ministério da Saúde. III Conferência Nacional de Saúde Mental: "cuidar sim, excluir não”. Relatório final. Brasília: Ministério da Saúde; 2001.

13. Gonçalves AM. A doença mental e a cura: um olhar antropológico. Millenium on.line 2004; (30). http://www.ipv.pt//millenium/millenium30/13. pdf.

14. Núcleo Técnico da Política Nacional de Humanização, Secretaria-Executiva, Ministério da Saúde. HumanizaSUS: equipe de referência e apoio matricial. Brasília: Ministério da Saúde; 2004. (Série B. Textos Básicos de Saúde).

15. Amarante PDC. Saúde mental e atenção psicossocial. Rio de Janeiro: Editora Fiocruz; 2007.

16. Secretaria de Atenção à Saúde, Ministério da Saúde. Saúde mental no SUS: acesso ao tratamento e mudança do modelo de atenção. Relatório de gestão, 2003-2006. Brasília: Ministério da Saúde; 2007.

Recebido em 13/Fev/2008

Versão final reapresentada em 28/Jan/2009 Aprovado em 18/Mai/2009 